\title{
SENSITIVITY ANALYSIS AND APPLICATION GUIDES FOR INTEGRATED BUILDING ENERGY AND CFD SIMULATION
}

\author{
Zhiqiang (John) Zhai \\ Department of Civil, Environmental, and Architectural Engineering \\ University of Colorado at Boulder \\ UCB 428, ECOT 441 \\ Boulder, CO 80309-0428, USA \\ Qingyan (Yan) Chen \\ School of Mechanical Engineering \\ Purdue University \\ 585 Purdue Mall, West Lafayette, IN 47907-2088, USA
}

\begin{abstract}
Building energy simulation (ES) and computational fluid dynamics (CFD) programs provide complementary information essential to evaluating building thermal performance. Integration of the two programs eliminates many model assumptions in separate applications and thus improves the quality of simulation results. This paper discusses the potential building and environmental characteristics that may affect the necessity and effectiveness of applying an ESCFD coupling simulation. These characteristics and the solution accuracy requirement determine whether a coupled simulation is needed for a specific building and which coupling method can provide the best solution with the compromise of both accuracy and efficiency. The study conducts a sensitivity analysis of the coupling simulation to the potential influential factors, based on which general suggestions on appropriate usage of the coupling simulation are provided.
\end{abstract}

\section{Introduction}

Building energy simulation (ES) and computational fluid dynamics (CFD) programs provide plentiful and complementary information about building thermal performance, such as space cooling and heating load, distributions of indoor air velocity, temperature, and contaminant concentrations. This information is important to assessing thermal comfort, indoor air quality, and energy consumption of a building. Due to the complementary nature of results provided by the two programs, attempts to integrate these two programs receive increasing attention recently (e.g., Negrao 1995, Beausoleil-Morrison 2000, Zhai 2003). It has been envisioned as a potential approach to eliminating simplification assumptions in each model and providing more accurate prediction on building behaviors (Zhai et al. 2002).

Zhai and Chen (2002, 2003 and 2005) explored the principles, methodologies, strategies, implementation, and performance of the ES-CFD thermal coupling. Their study proved that a unique coupled solution exist in theory but different coupling methods may lead to different solution performance in terms of computing accuracy, stability and speed. It verified that the data 
coupling method, which transfers enclosure interior surface temperatures from ES to CFD and returns convective heat transfer coefficient and indoor air temperature gradients from CFD to ES, is the most straightforward, reliable and efficient coupling method. The study further proposed the staged coupling strategies to reduce the total computing time of a coupling simulation. A prototype of an integrated ES-CFD building simulation tool, implementing all the proposed coupling strategies, was developed. The performance of the program has been examined against experimental data and compared with no-coupling simulations.

However, the previous studies did not provide answers to the questions that are most important to building designers and engineers who may think of using the coupling simulation:

(1) Under which circumstance is an integrated ES-CFD simulation necessary? Or under which circumstance is a separate ES and CFD simulation sufficient? What is the improvement-costrate of coupling simulation?

(2) Which coupling strategy should be used?

(3) Which coupling frequency should be used?

This paper addresses these questions with a sensitivity study of the coupling simulation to potential building and environmental influential factors. It will provide essential and practical knowledge of coupling simulation to developers and users of ES-CFD coupling programs.

\section{Coupling-Relevant Building and Environmental Characteristics}

Building characteristics and simulation goals determine the most appropriate coupling simulation strategy for a particular building. Building characteristics that may influence building energy consumption have been extensively explored (e.g., Korobov 1960, Lomas and Eppel 1994, and Saporito 1999). However, not all these building characteristics have significant effect on the determination of a suitable coupling simulation strategy. Changes of some building characteristics, such as building shape, may not explicitly affect the performance of a coupling simulation.

In ES-CFD thermal coupling, the extent of connection between building energy and airflow models determines whether a coupling simulation is necessary and which coupling strategy is most appropriate for a building. More specifically, the necessity and effectiveness of ES-CFD coupling are determined by:

(1) the dependence of building envelope heat transfer and cooling/heating load on indoor air movement and air temperature stratification;

(2) the sensitivity of indoor air movement and air temperature stratification to thermal boundary conditions.

In general, a coupling simulation is desired if the inter-coupled information of ES and CFD is important to either ES or CFD or both. The dynamic behaviors of the inter-coupled information determine the best coupling strategy. For instance, a one-step or two-step static coupling process is sufficient if the inter-coupled data (e.g., surface temperature) is constant or has small change.

Hence, building and environmental conditions from outdoor to indoor, whose variation may influence the inter-coupled variables (e.g., convective heat from enclosures), need be 
examined for possible effects on building energy and airflow simulation. These building and environmental characteristics primarily include:

- Outdoor weather conditions;

- Building envelope properties;

- Building window-wall area ratio;

- Building operating conditions;

- Space sizes;

- Internal loads; and

- HVAC systems.

These potential influential factors can be grouped into five categories according to their macro-effects on buildings, as summarized in Table 1. The first category is environmental conditions that are mainly represented by outdoor air temperature and solar radiation for thermal consideration. The second is different HVAC systems used, such as radiation heating and cooling systems, traditional mixing HVAC systems, displacement ventilation systems, and natural/hybrid ventilation systems. The third is building occupying and system operating conditions that represent the capacity and dynamics of building energy consumption mainly determined by building functions. The fourth is building envelope information including material properties and window-wall area ratio. The last one is building sizes with different floor areas and ceiling heights. Combination of these characteristics determines the whole building thermal and indoor airflow behaviors, whereas individual characteristics may have distinctive influence. It is important to investigate the effect of these building and environmental characteristics on the coupling simulation.

Table 1 Coupling-relevant building and environmental characteristics and potential variations

\begin{tabular}{|l|l|l|}
\hline Category & Characteristics & Potential Variations \\
\hline Environmental conditions & outdoor air temperature & $\begin{array}{l}\text { large fluctuation, } \\
\text { small fluctuation }\end{array}$ \\
\cline { 2 - 3 } & solar radiation & $\begin{array}{l}\text { yes (summer design day), } \\
\text { no (winter design day) }\end{array}$ \\
\hline \multirow{3}{*}{ HVAC systems } & radiation heating/cooling & \\
\cline { 2 - 3 } & mixing ventilation & CAV, VAV \\
\cline { 2 - 3 } & displacement ventilation & CAV, VAV \\
\cline { 2 - 3 } & natural/hybrid ventilation & \\
\hline Occupying and operating conditions & internal load & heavy, medium, light \\
\cline { 2 - 3 } & schedule & $\begin{array}{l}\text { day \& night (residential), } \\
\text { day only (commercial) }\end{array}$ \\
\hline \multirow{2}{*}{ Building envelope properties } & wall, ceiling, floor & heavy, medium, light \\
\cline { 2 - 3 } & window-wall area ratio & full, partial, none \\
\hline Building sizes & floor area & regular, large \\
\cline { 2 - 3 } & ceiling height & regular, high \\
\hline
\end{tabular}




\section{Sensitivity Study of Coupling Simulation}

This study conducts a sensitivity analysis of the coupling simulation to the building and environmental characteristics. The main objectives of the sensitivity study are to address:

(1) whether a coupled simulation is necessary for a building with specific characteristics;

(2) which coupling strategy can provide a best solution (in terms of accuracy and efficiency) for a building with specific characteristics.

\subsection{Model Descriptions}

The sensitivity study first created a base model, which represents a typical one-occupant office in a typical office building. The office is in a middle floor of the building, with completely identical neighboring rooms. The geometry and configuration of the office is illustrated in Figure 1. The room has one south-facing exterior wall with a large window. Table 2 lists the primary characteristic parameters of the base model. The investigation focuses on ventilated buildings with different HVAC systems because previous studies (Zhai and Chen 2005) indicate that coupling simulation has marginal benefits for buildings with natural convection. The study only investigates the cooling scenario in summer design day as the heating scenario has analogous behaviors.

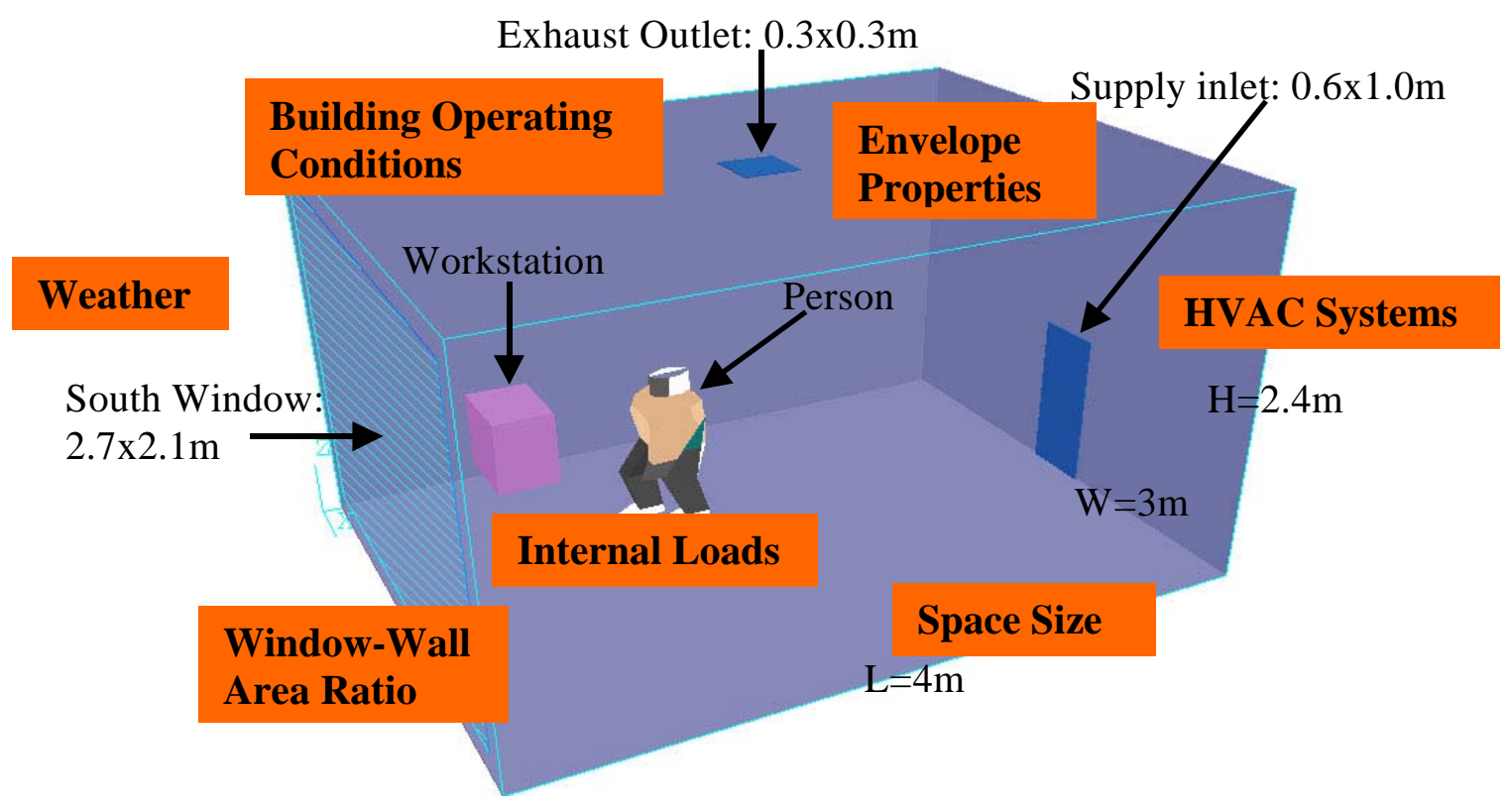

Figure 1 Schematic of the one-occupant office

Upon the base model, the building and environmental characteristics were then adjusted individually to examine the effect of each factor on the whole building system. Ideally, the sensitivity study needs a continuous change of each characteristic parameter within a reasonable range to acquire sufficient information for quantitative assessment of the influence of individual characteristics. This demands tremendous computing efforts. In addition, it is difficult to 
quantify the change of some variables, such as solar radiation. The present study merely tests a limited number of variations for each parameter to accumulate basic and qualitative knowledge of appropriate usage of the coupling simulation. Particularly, the investigation examines extreme conditions for most variables, such as with and without solar radiation, with and without window, so as to qualitatively analyze the influence of each character on coupling simulation. Table 2 summarizes the major variation cases studied for the ventilated room.

To demonstrate the benefits and costs of a coupled simulation over a non-coupled simulation, both simulations are performed for the base case and each variation case. In the coupled simulation, all types of the coupling strategies implemented in the E+MIT-CFD program (Zhai and Chen 2005) are used to identify the most appropriate coupling process for a particular building. More specifically, for the base case and each variation case, the following simulations are performed in sequence:

(1) Non-coupled simulation;

(2) Coupled simulation with:

- Full dynamic coupling (FDC);

- Quasi dynamic coupling (QDC);

- One-time-step dynamic coupling (ODC);

- Dynamic bin coupling (DBC).

\subsection{Results Analysis}

With the dynamic boundary conditions (supply airflow rate and surface temperatures) provided by ES, CFD in the coupled simulation can effectively predict the dynamic indoor environment through the entire design day. As an example, Figure 2 presents the distributions of indoor air velocity and temperature of the base case at the peak load time of 13:00. The airflow pattern exhibits the typical flow characteristics of displacement ventilation: the large circulation above the floor and the significant vertical air temperature gradient $\left(>5^{\circ} \mathrm{C}\right)$.
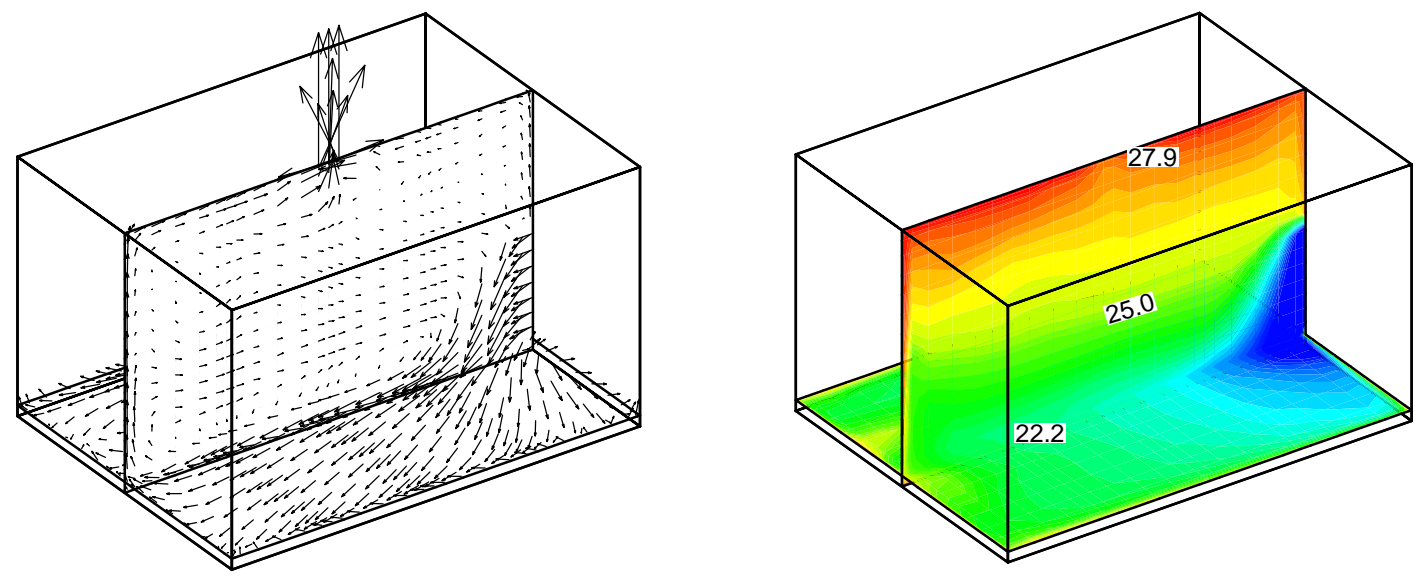

Figure 2 Velocity and temperature distribution in the office with back-wall-supply displacement ventilation system at $13 \mathrm{pm}$ of the summer design day in Boston (base case) 
Table 2 Parameter summary for the base and variation cases in the sensitivity study

\begin{tabular}{|c|c|c|c|}
\hline & \multicolumn{2}{|c|}{$\begin{array}{c}\text { Base Case } \\
\end{array}$} & Variation Cases \\
\hline \multirow[t]{4}{*}{$\begin{array}{l}\text { HVAC } \\
\text { systems }\end{array}$} & \multirow[t]{4}{*}{$\begin{array}{l}\text { Side-wall- } \\
\text { supply } \\
\text { displacement } \\
\text { ventilation }\end{array}$} & \multirow{4}{*}{$\begin{array}{l}\text { One back-wall box } \\
\text { diffuser, } \\
\text { VAV system, } \\
\mathrm{T}_{\text {supply }}=16^{\circ} \mathrm{C}, \\
\mathrm{T}_{\text {room }}=25^{\circ} \mathrm{C}\end{array}$} & $\begin{array}{l}\text { V-1: Back-wall-supply } \\
\text { displacement ventilation, one back- } \\
\text { wall box diffuser, CAV system, } \\
\dot{\mathrm{V}}=0.12 \mathrm{~m}^{3} / \mathrm{s}\end{array}$ \\
\hline & & & $\begin{array}{l}\text { V-2: Ceiling-supply mixing } \\
\text { ventilation (back-wall bottom } \\
\text { return), one ceiling-mounted } \\
\text { horizontally-supply diffuser, CAV } \\
\text { system, } \dot{\mathrm{V}}=0.36 \mathrm{~m}^{3} / \mathrm{s}\end{array}$ \\
\hline & & & $\begin{array}{l}\text { V-3: Ceiling-supply mixing } \\
\text { ventilation (back-wall bottom } \\
\text { return), one ceiling-mounted } \\
\text { vertically-supply diffuser, VAV } \\
\text { system, } \mathrm{T}_{\text {supply }}=18^{\circ} \mathrm{C}\end{array}$ \\
\hline & & & $\begin{array}{l}\text { V-4: Floor-supply displacement } \\
\text { ventilation, two floor square swirl } \\
\text { supply diffusers, VAV system, } \\
\mathrm{T}_{\text {supply }}=19^{\circ} \mathrm{C} \\
\end{array}$ \\
\hline \multirow[t]{2}{*}{$\begin{array}{l}\text { Environmental } \\
\text { conditions }\end{array}$} & $\begin{array}{l}\text { Outdoor air } \\
\text { temperature }\end{array}$ & \multirow[t]{2}{*}{$\begin{array}{l}\text { Boston summer } \\
\text { design day conditions }\end{array}$} & $\begin{array}{l}\text { V-5: Boston summer cloudy day } \\
\text { (no solar radiation) }\end{array}$ \\
\hline & Solar radiation & & \\
\hline \multirow[t]{2}{*}{$\begin{array}{l}\text { Occupying } \\
\text { and operating } \\
\text { conditions }\end{array}$} & Internal loads & $\begin{array}{l}100 \mathrm{~W} \text { occupant, } \\
270 \mathrm{~W} \text { computer } \\
30 \% / 70 \% \text { radiation/ } \\
\text { convection split }\end{array}$ & V-6: No internal objects \\
\hline & Schedule & $\begin{array}{l}\text { Day and night ( } 24 \\
\text { hours) }\end{array}$ & V-7: Day only (9:00-18:00) \\
\hline \multirow[t]{5}{*}{$\begin{array}{l}\text { Building } \\
\text { envelope } \\
\text { properties }\end{array}$} & \multirow[t]{2}{*}{$\begin{array}{l}\text { Wall, ceiling, } \\
\text { floor }\end{array}$} & \multirow{2}{*}{$\begin{array}{l}\text { R-19 ceiling and } \\
\text { floor (middle floor), } \\
\text { R-13 walls, } \\
\text { light materials (no } \\
\text { thermal mass) }\end{array}$} & $\begin{array}{l}\text { V-8: R-19 ceiling and floor } \\
\text { (middle floor), R-13 walls, heavy } \\
\text { materials (thermal mass) }\end{array}$ \\
\hline & & & V-9: Top floor (R-19 roof) \\
\hline & \multirow[t]{3}{*}{ South window } & \multirow[t]{3}{*}{$\begin{array}{l}2.7 \times 2.1=5.67 \mathrm{~m}^{2} \\
\text { clear } 6 \mathrm{~mm} \text { glass }\end{array}$} & $\begin{array}{l}\text { V-10: No window but R-13 south } \\
\text { wall }\end{array}$ \\
\hline & & & $\begin{array}{l}\text { V-11: No window but R-7 south } \\
\text { wall }\end{array}$ \\
\hline & & & $\begin{array}{l}\text { V-12: Three-piece window and } \\
\text { walls in simulation: top, middle, } \\
\text { bottom }\end{array}$ \\
\hline \multirow[t]{2}{*}{ Building sizes } & Floor area & $3 \times 4=12 \mathrm{~m}^{2}$ & $\begin{array}{l}\text { V-13: Quadruple floor area } \\
6 \times 8=48 \mathrm{~m}^{2}\end{array}$ \\
\hline & Ceiling height & $2.4 \mathrm{~m}$ & V-14: Double ceiling height $4.8 \mathrm{~m}$ \\
\hline
\end{tabular}


Figure 3(a) presents the dynamic cooling load of the base case in the summer design day predicted with and without coupling. Less cooling energy is required in the nighttime due to the cool outdoor temperature and no solar gain. The peak cooling energy is predicted around 13:00 by both coupled and non-coupled simulations, while the coupled simulation produces a larger peak load than the non-coupled one. However, the total cooling load predicted by the coupled simulation has only marginal increase from that predicted by the non-coupled simulation for all the displacement ventilation cases, as revealed by Figure 4. This is mainly because:

(1) The dominant buoyancy-driven indoor airflow has relatively small convective heat transfer coefficients for most building enclosures except the floor. These coefficients can be reasonably simulated by the natural convection empirical correlations used in the ES program, as compared in Table 3.

(2) Because of the cold supply air near the floor, the floor has a relatively lower temperature than the other opaque surfaces, instead of a higher temperature from the non-coupled simulation. The low floor temperature leads to about $1^{\circ} \mathrm{C}$ temperature drop for all the other opaque surfaces by radiation effect, resulting in less heat transferred from these surfaces into the indoor space. On the other hand, explicit temperature gradient and large convection coefficient at the floor caused by displacement ventilation introduce more heat into the office space. The reduction of heat gains from the walls offset the increase of heat gain from the floor, resulting in the limited increase of the total cooling load in the coupled simulation.

The coupled simulation, however, predicts a much smaller supply air flow rate than the non-coupled simulation for the displacement ventilation cases with VAV systems, as evidenced by Figure 5. This is attributed to the significant indoor air temperature stratification caused by displacement ventilation. The actual exhaust air temperature at the ceiling, predicted by CFD, is much higher than the mean room air temperature, as illustrated by Figures 3(b), resulting in less supply airflow requirement. The study indicates that the difference of total supplied air mass between the coupled and non-coupled results can be as large as over $40 \%$. This implies that the fan and chiller could be oversized if using the non-coupled results. The high ceiling case (Case $\mathrm{V}$-14), which has the most significant vertical temperature gradient (about $12^{\circ} \mathrm{C}$ ), has about $42 \%$ deviation of predicted supply air mass between the coupled and non-coupled results. The improvement with the coupling is not significant for the cases with less cooling loads because of the corresponding small indoor air temperature gradients. Note that the floor-supply displacement ventilation case (Case $\mathrm{V}$-4) has a larger difference of total supplied air mass between coupled and non-coupled simulations than the base case. This indicates a larger difference of the exhaust air temperature and mean room air temperature for the floor-supply displacement ventilation, as verified by Figure 6. Figure 6 and 7(a) also testify that the floorsupply displacement ventilation will not cause more serious thermal discomfort of air draft and cold feet than the back-wall-supply displacement ventilation unless very close to the diffusers. 


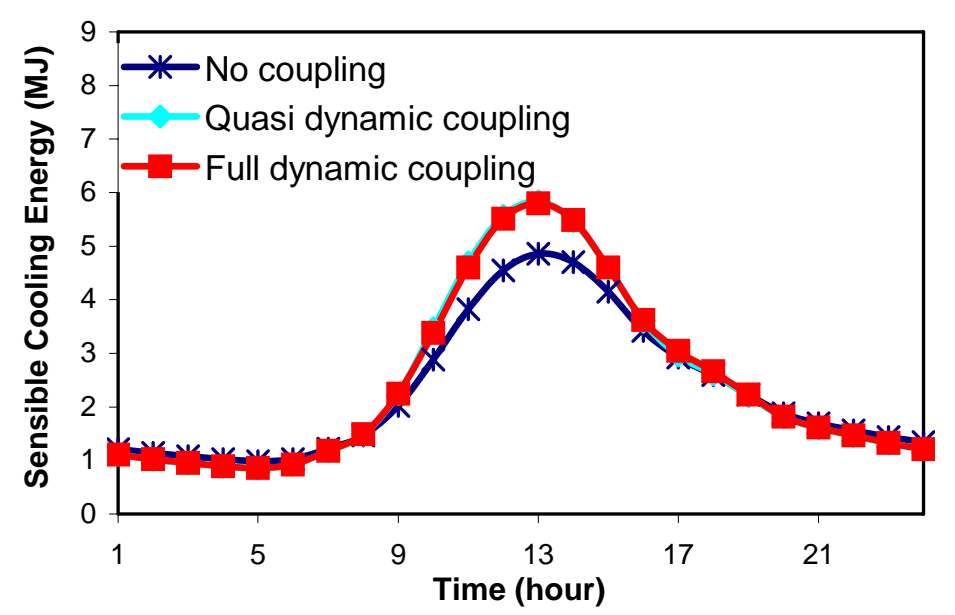

(a)

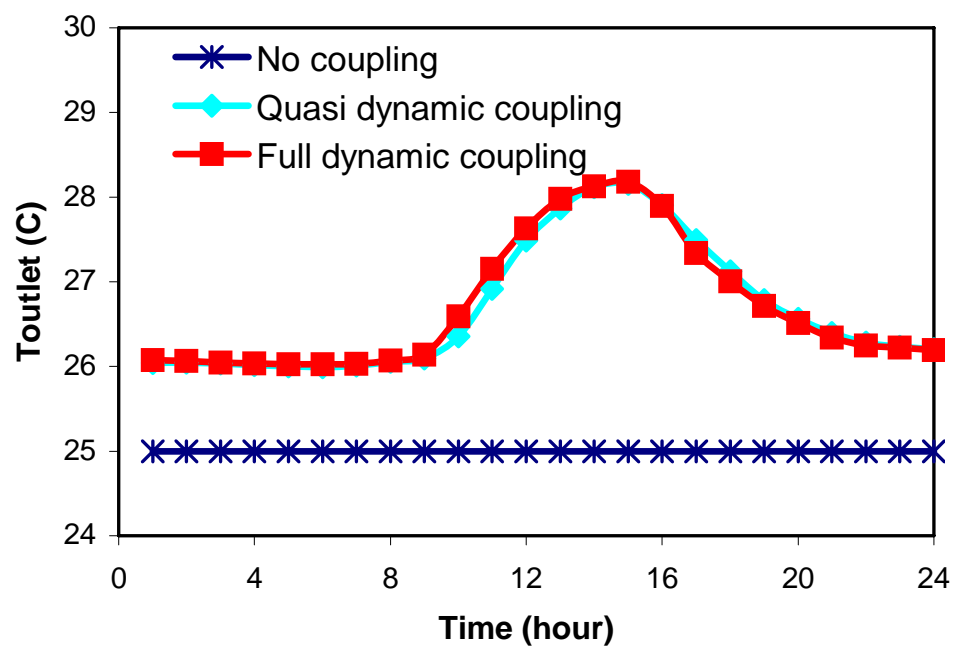

(b)

Figure 3 Predicted (a) sensible cooling load and (b) room exhaust air temperature of the base case during the summer design day with coupled and non-coupled simulations

Table 3 Daily-averaged enclosure interior surface temperature and convection coefficients predicted for the base case by coupled and non-coupled simulations

\begin{tabular}{|c|r|r|r|r|}
\hline \multirow{2}{*}{ Enclosure } & \multicolumn{2}{|c|}{ Non-coupled results } & \multicolumn{2}{c|}{ Coupled results } \\
\cline { 2 - 5 } & $\begin{array}{c}\mathrm{T}_{\text {surface }} \\
\left({ }^{\circ} \mathrm{C}\right)\end{array}$ & $\begin{array}{c}\mathrm{h} \\
\left(\mathrm{W} / \mathrm{m}^{2}{ }^{\circ} \mathrm{C}\right)\end{array}$ & $\begin{array}{c}\mathrm{T}_{\text {surface }} \\
\left({ }^{\circ} \mathrm{C}\right)\end{array}$ & $\begin{array}{c}\mathrm{h} \\
\left(\mathrm{W} / \mathrm{m}^{2}{ }^{\circ} \mathrm{C}\right)\end{array}$ \\
\hline South window & 25.7 & 1.9 & 25.3 & 3.0 \\
\hline East wall & 28.5 & 1.9 & 27.3 & 2.2 \\
\hline North wall & 28.4 & 1.9 & 27.2 & 2.1 \\
\hline West wall & 28.5 & 1.9 & 27.3 & 2.2 \\
\hline Floor & 29.2 & 2.3 & 26.5 & 17.6 \\
\hline Roof & 28.7 & 1.1 & 27.6 & 0.3 \\
\hline
\end{tabular}




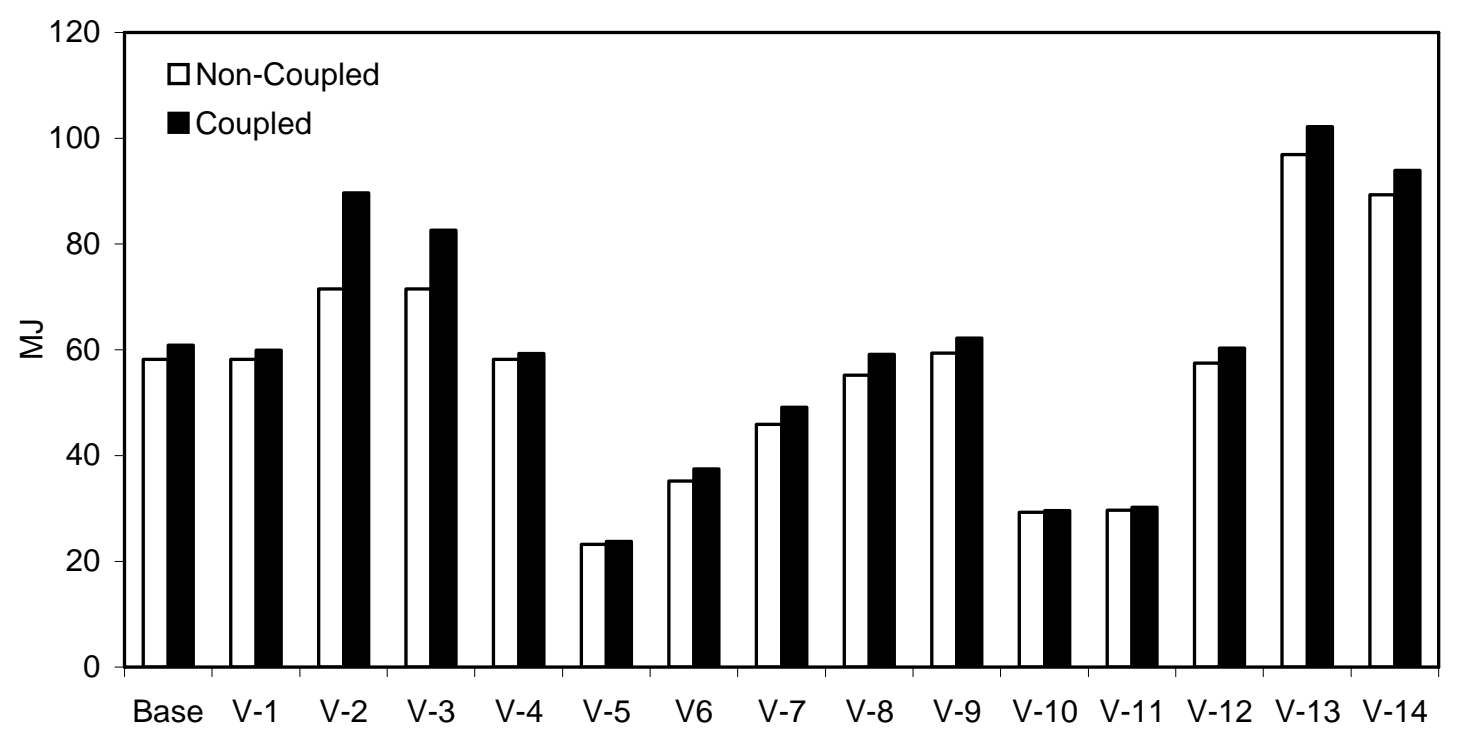

Figure 4 Predicted total cooling load from coupled and non-coupled simulations

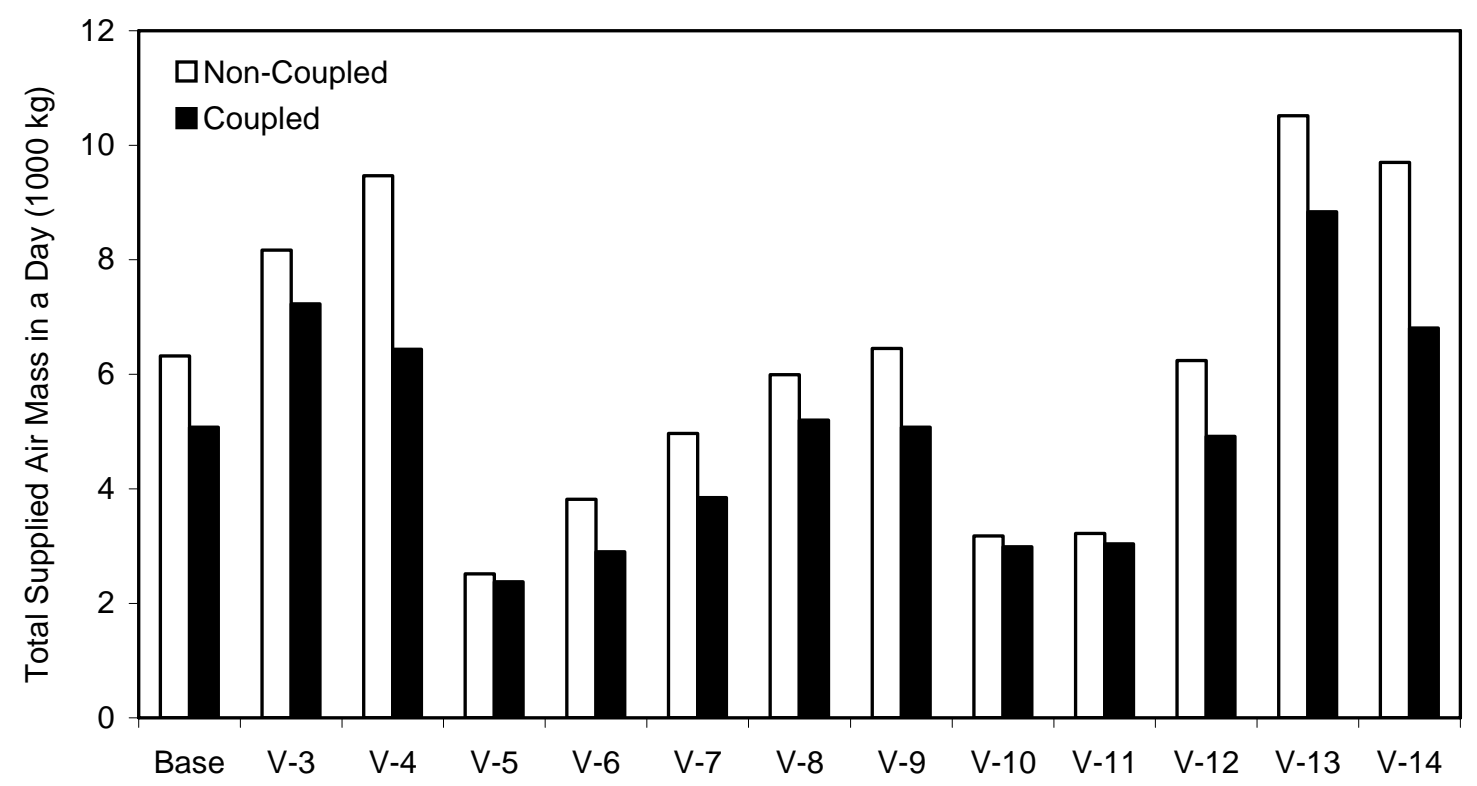

Figure 5 Predicted total supplied air mass in the summer design day for different cases with VAV systems from coupled and non-coupled simulations 


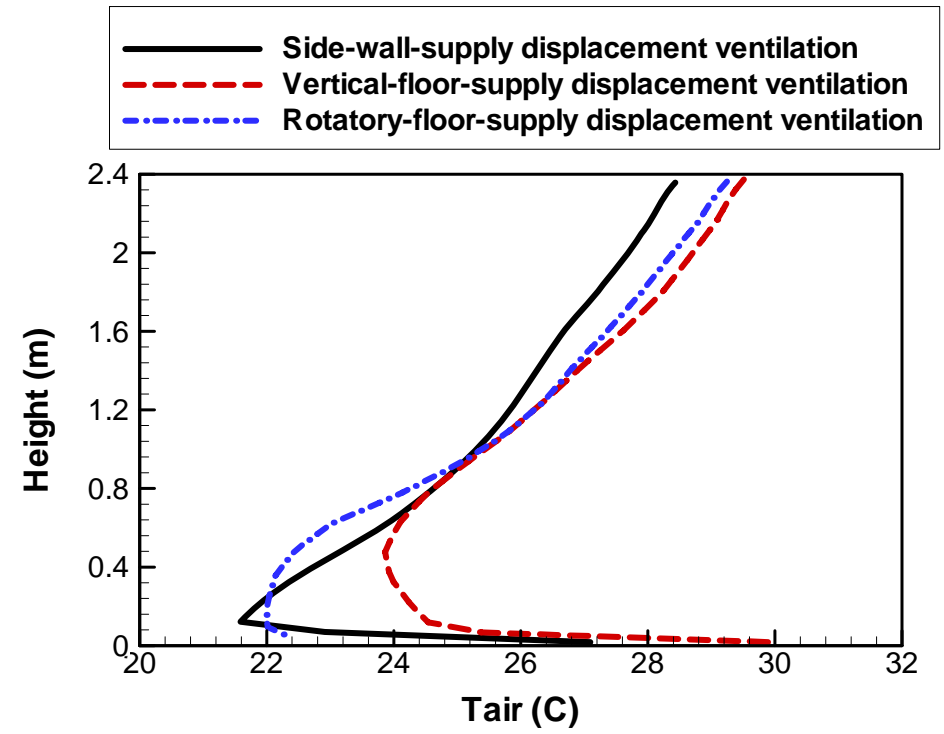

Figure 6 Temperature profiles at the room center at 12:00 pm

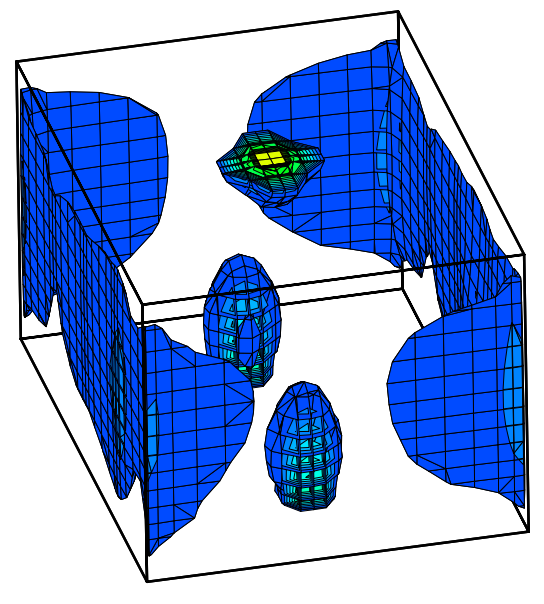

(a)

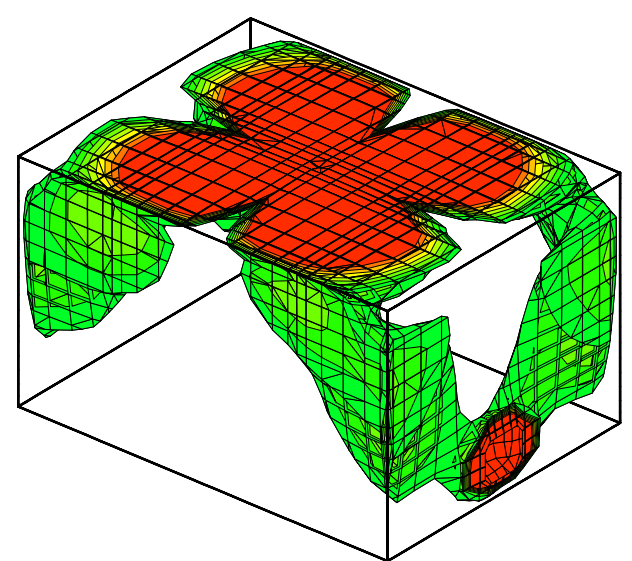

(b)

Figure 7 (a) Indoor airflow speed contour (>0.2m/s) at $12 \mathrm{pm}$ in the office with floor-supply displacement ventilation system (Case $V$-4) and (b) indoor airflow speed contour $(>0.5 \mathrm{~m} / \mathrm{s})$ at 12 pm in the office with ceiling-horizontally-supply mixing ventilation system (Case V-2) 
Figure 4 also shows that the predicted cooling loads of the mixing ventilation cases (Case $\mathrm{V}-2$ ands V-3) from the coupled simulations are perceptibly different from those from noncoupled simulations. This is attributed to the new convection coefficients and the indoor air temperature gradients transferred from CFD to ES. The case with horizontal-supply diffuser (Case V-2) has about 20\% prediction difference of the cooling load. The cold supply air attaches to the enclosure surfaces and flows downward to the floor, enhancing the convection between the cold air and surfaces, as illustrated in Figure 7(b). A separate ES can not simulate the effect of air supply direction on building load calculation because of the perfect mixing assumption.

The study investigates the influence of the isothermal surface assumption on the coupled solutions by dividing each wall and window into three pieces from top to bottom (Case V-12). The results reveal that this assumption has little impact on the coupled simulation although explicit surface temperature gradients do exist. As revealed by Figure 8, the uniform surface temperature equals the average of the gradient values, and the air temperature profiles close to the surface from two simulations are almost the same. The study further finds that exposing the ceiling (roof) to the outdoor environment (Case V-9) will not change the simulation results. This is probably because of good insulation of the ceiling and weak convective heat at the ceiling due to the slow air movement and small temperature difference between the ceiling and the air close to the ceiling.

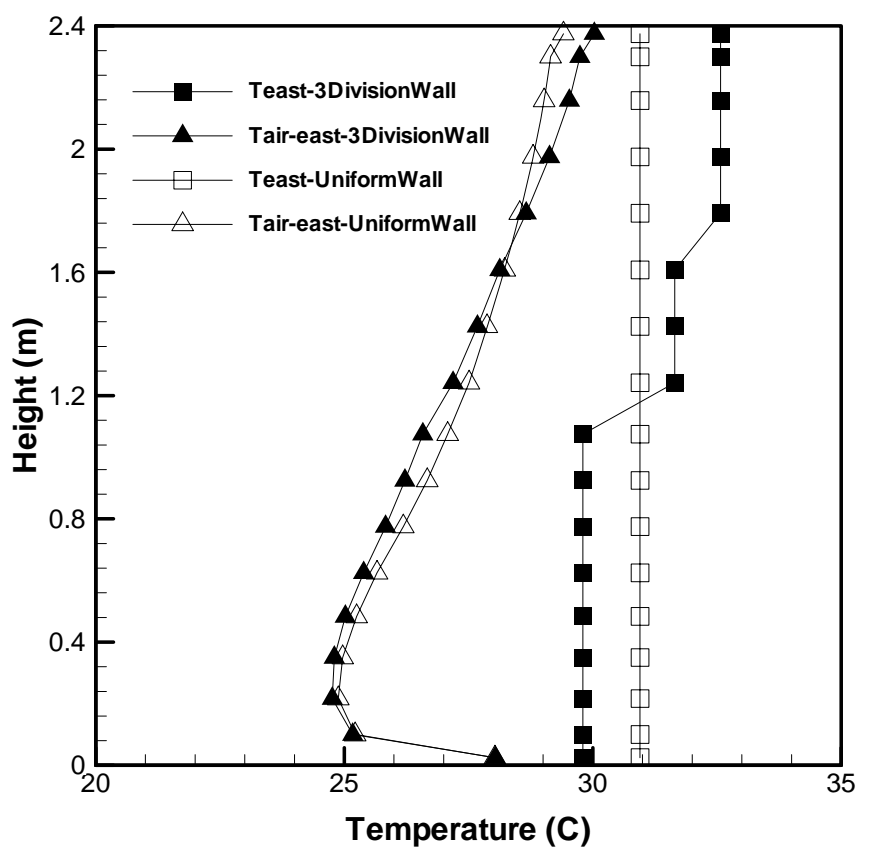

Figure 8 Profiles of east wall temperature and air temperature close $(0.025 \mathrm{~m})$ to the east wall at $12 \mathrm{pm}$ with isothermal and non-isothermal surface assumptions

The study intensively compares the performance of different coupling strategies. Figure 3 demonstrates that quasi dynamic coupling can provide similar results as full dynamic coupling. In practice, more internal iterations in CFD may be needed to reach a converged solution at every coupling step. Figure 9 presents the floor temperature of the case with R-13 south wall 
(Case V-10) predicted by using different coupling methods but without applying coupling to the warm-up period. The figure clearly demonstrates that large difference exists between the coupled and non-coupled results. One-time-step dynamic coupling provides somehow different results because the CFD results obtained at 0:00 (the beginning of a day) may not be appropriate for the rest of the day. Quasi dynamic coupling with less CFD iterations shows the explicit converging process during the morning hours and tends to approach the full dynamic coupling results in the later afternoon. Quasi dynamic coupling with more CFD iterations has results very close to those from full dynamic coupling except at the initial hours because of the historical thermal effect. Both quasi dynamic and full dynamic coupling simulations show the importance of the coupling for the warm-up days because otherwise inconsistent solutions are obtained at 0:00 and 24:00.

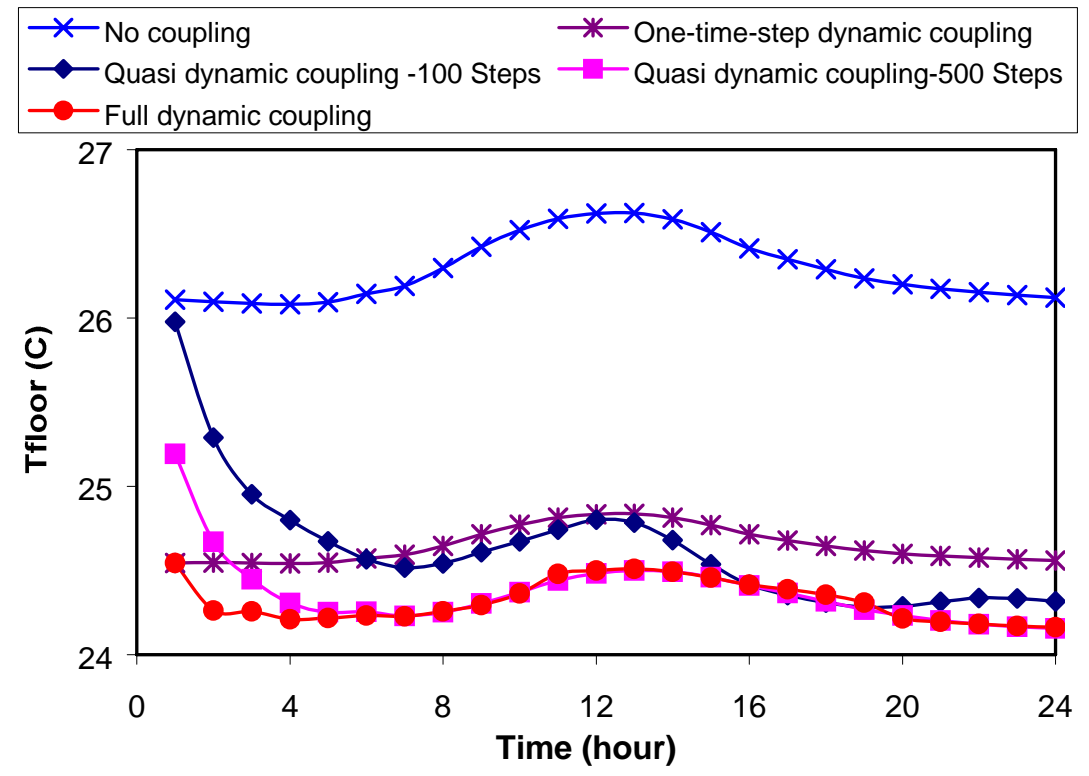

Figure 9 Predicted floor temperature for the R-13 south wall case (Case V-7)

The same conclusions are found for the other cases. As an example, Figure 10 presents the predicted floor temperature for the case with heavy envelope materials (Case V-8) during the summer design day. The results, along with the computing time recorded in Table 4, further verify that:

(1) Although fast, one-time-step coupling is not sufficient for accurate prediction of dynamic building behaviors, even for the cases with slight fluctuation of thermal performance.

(2) Quasi dynamic coupling with sufficient CFD iterations can provide results similar to those from full dynamic coupling. Building airflow characteristics determine appropriate CFD internal iterations. Buildings with instable airflow such as those with dominant buoyancydriven airflow usually require more iterations in each CFD to achieve a converged and stable solution. This may reduce the time benefit of quasi dynamic coupling strategy. In addition, if building envelope or indoor environment encounters significant changes between two time steps, as during the start-up and shut-down period, using CFD results at the last time step to the current time step of ES may cause serious prediction problems.

(3) Applying coupling simulation for warm-up days is essential for design day simulation; otherwise inconsistent solutions are obtained at 0:00 and 24:00. Dynamic bin coupling 
method can be used for warm-up days due to similar environmental and operating conditions, in which coupling simulation is only used for the first day of the warm-up period and the stored dynamic CFD information is then used for the rest of the warm-up days. The study shows that the results obtained by using this method are the same as those obtained by using coupling simulation for all the days, while the total computing time is reduced by more than half.

(4) Coupling simulation at frequency of every two hours can provide reasonably good solutions while saving about half of the computing time. Coupling simulation at frequency of every three hours may result in obviously non-smooth solutions.
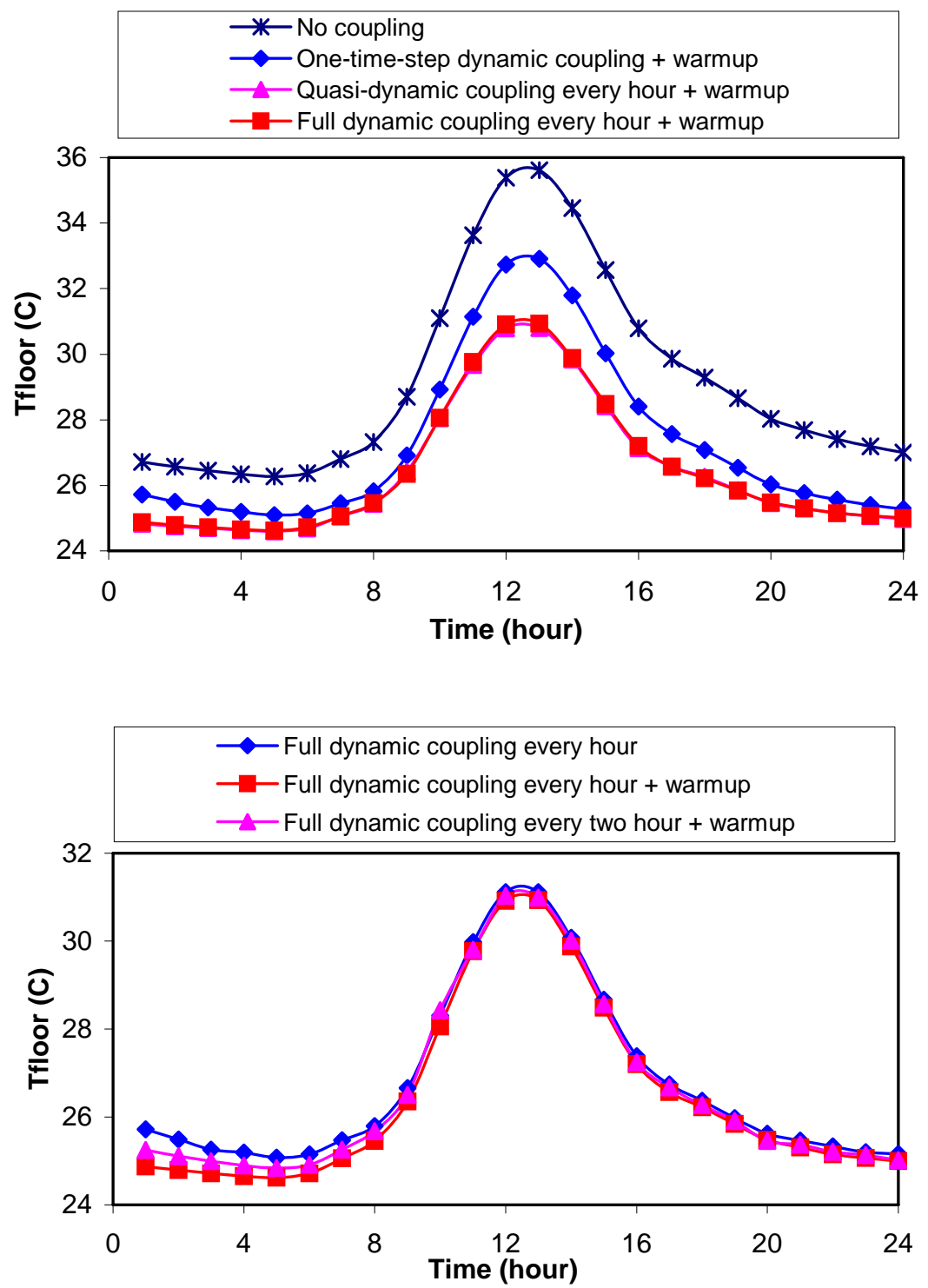

Figure 10 Predicted floor temperature for the case with heavy envelope materials (Case V-8) using different dynamic coupling strategies 
Table 4 Computing time for the case with heavy envelope materials (Case V-8) with different dynamic coupling strategies

\begin{tabular}{|l|l|}
\hline Dynamic coupling strategy & Computing time \\
\hline FDC-EveryHour-NoWarmupCoupling: 100 CFD Steps & 4 hours 46 minutes \\
\hline FDC-EveryHour-WarmupCouplingforFirstDay: 100 CFD Steps & 9 hours 51 minutes \\
\hline FDC-Every2Hours-WarmupCouplingforFirstDay: 100 CFD Steps & 5 hours 40 minutes \\
\hline QDC-EveryHour-NoWarmupCoupling: 500 CFD Steps & 3 hours 53 minutes \\
\hline QDC-EveryHour-WarmupCouplingforFirstDay: 500 CFD Steps & 7 hour 57 minutes \\
\hline QDC-EveryHour-WarmupCouplingforFirstDay: 100 CFD Steps & 1 hour 45 minutes \\
\hline QDC-Every2Hour-WarmupCouplingforFirstDay: 500 CFD Steps & 3 hour 39 minutes \\
\hline QDC-Every2Hour-WarmupCouplingforFirstDay: 100 CFD Steps & 43 minutes \\
\hline OTS-0am-WarmupCouplingforFirstDay: 100 CFD Steps & 48 minute \\
\hline
\end{tabular}

\section{General Guides on ES-CFD Coupling Simulation}

The sensitivity study, along with the previous validation and application studies (Zhai and Chen 2005), forms the basic knowledge of selecting an appropriate simulation approach for a specific building. The sensitivity analysis indicates that buildings with significant indoor airflow, such as those with mixing ventilation, may encounter considerable difference of predicted energy consumption by using coupling simulation. Perceptible indoor air temperature stratification may influence slightly calculated cooling and heating load but significantly supply airflow rate. The building and environmental characteristics that cause notable change of envelope and indoor air conditions determine the coupling requirement between ES and CFD.

In practice, building and environmental characteristics and solution accuracy requirement together determine the best simulation strategy. Usually, at the early stage of a building design, a non-coupled simulation may be sufficient as many building details have not been determined and a quick and rough prediction of building performance is desired. When the design advances further, a more accurate simulation of integrated building behaviors is expected and a coupled simulation may be required.

A coupled simulation provides a more accurate and informative prediction of building performance but needs a much longer computing time. It is user's choice to decide the best compromise between accuracy and cost. This study summarizes in Table 2 the average solution improvement ranges and computing costs for different scenarios by using the developed E+MITCFD program with a PIII-900 desktop personal computer (Zhai and Chen 2005). The usual experiment measurement errors are also included in the table as a reference. The data of Table 5 may vary with cases studied and methodologies used, but provides users a gross sense about the potential benefits and cost of a coupled simulation. 
Table 5 Average solution improvement possibilities and computing costs of coupling simulation

\begin{tabular}{|c|c|c|c|}
\hline & $\begin{array}{l}\text { Natural } \\
\text { Convection }\end{array}$ & $\begin{array}{l}\text { Mixing } \\
\text { Ventilation }\end{array}$ & $\begin{array}{l}\text { Displacement } \\
\text { Ventilation }\end{array}$ \\
\hline$\left|\mathrm{T}_{\text {room-couple }}-\mathrm{T}_{\text {room-noncouple }}\right|\left({ }^{\circ} \mathrm{C}\right)$ & $\begin{array}{l}\sim 0.5 \\
\end{array}$ & $\sim 2$ & $\sim 2$ \\
\hline $\mathrm{T}_{\text {surface-couple }}-\mathrm{T}_{\text {surface-noncouple }} \mid\left({ }^{\circ} \mathrm{C}\right)$ & $\sim 0.5$ & $\sim 1-5$ & $\sim 2-5$ \\
\hline$\left|\frac{\mathrm{Q}_{\text {couple }}-\mathrm{Q}_{\text {noncouple }}}{\mathrm{Q}_{\text {couple }}}\right|$ & $\sim 5-10 \%$ & $\sim 10-25 \%$ & $\sim 2-5 \%$ \\
\hline$\frac{\dot{\mathrm{M}}_{\text {couple }}-\dot{\mathrm{M}}_{\text {noncouple }}}{\dot{\mathrm{M}}_{\text {couple }}}$ & & $\sim 10-30 \%$ & $\sim 20-50 \%$ \\
\hline $\begin{array}{l}\text { Computing cost for each simulation day with } \\
\text { hourly full dynamic coupling (second/grid) }\end{array}$ & $0.1-0.2$ & $2.0-2.6$ & $2.0-2.7$ \\
\hline \multirow{2}{*}{\begin{tabular}{|l|l} 
Experiment measurement accuracy & T \\
\cline { 2 - 3 } & $\mathrm{Q}$
\end{tabular}} & $\pm 0.2-0.5^{\circ} \mathrm{C}$ & $\pm 0.5-1^{\circ} \mathrm{C}$ & $\pm 0.3^{\circ} \mathrm{C}$ \\
\hline & $\pm 2-10 \%$ & $\pm 10 \%$ & \\
\hline
\end{tabular}

Note: $\mathrm{T}$ is the peak temperature. $\mathrm{Q}$ is the heating/cooling energy requirement. $\dot{\mathrm{M}}$ is the supply air mass flow rate for VAV systems. Measurement accuracy data are from the experiment reports by Lomas et al. (1994), Hiramatsu et al. (1996), Fisher (1995), Wallenten (1998), and Chen et al. (1998).

On the basis of the sensitivity study, the study further summarizes some basic rules for the application of coupling simulation, as follows.

(1) Under which circumstance is a separate ES and CFD sufficient?

a. building design and calculation is at the early stage;
b. building has fairly mixed indoor environment and has properly calibrated convective heat
transfer coefficient correlations;
c. indoor airflow is dominated by internal heat gains.
For these calculations, a one-way or two-way static coupling or a static bin coupling can always be used to manually exchange relevant information between ES and CFD as needed. The static coupling avoids the substantial iteration between ES and CFD and thus significantly reduces the computing cost.

(2) Under which circumstance is a dynamic coupling necessary?

a. building has perceptible indoor air temperature stratification and/or indoor air movement;

b. indoor air environment is heavily dependent on the thermal boundary conditions.

(3) Which coupling strategy should be used?

a. In general, one-time-step dynamic coupling is not appropriate for most cases with dynamic environmental and/or operating conditions. But it is ideal for cases with small fluctuations of building thermal behaviors, such as the case with good insulation that makes indoor environment receive less influence from varying outdoor conditions and the case of winter design day that has constant outdoor conditions. One-time-step dynamic coupling uses much less computing time than full dynamic coupling. 
b. Full dynamics coupling performs the most complete coupling between ES and CFD and thus results in the most accurate and informative prediction of building performance. However, it is most expensive in computing cost.

c. If a building has no significant change of thermal behaviors, quasi-dynamic coupling can provide results very similar to full dynamic coupling and largely reduce computing time for most cases because of no iteration in each coupling step. However, for some cases with unstable airflows, more iterations inside CFD is required to reach a converged solution at each coupling step, resulting in very limited time saving of quasi-dynamic coupling. For buildings with significant change of thermal behaviors, using CFD results at the previous step (especially with large time steps) for the current step of ES may lead to considerable prediction errors.

d. Bin coupling method is a highly efficient coupling strategy. Static bin coupling is recommended if reliable bins are available and dynamic indoor environment is not concerned. Dynamic bin coupling is a realistic and effective coupling approach, which produces real-time bins for typical simulation days. The dynamic bins stored can then be used for similar days. Quasi-dynamic or full dynamic or even one-time-step dynamic coupling can be used to produce the dynamic bins in typical days. Dynamic bin coupling can dramatically reduce computing cost, especially for simulations on a long term (e.g., a year). Similar environmental and building operating conditions are the premises to the adoption of this approach.

(4) Which coupling frequency should be used?

The coupling frequency of every two hours is a minimum requirement in order to acquire a smooth and reasonable solution, although hourly coupling is suggested. More frequent exchange of information between ES and CFD may not be necessary because of the small change of the inter-coupled conditions between two coupling steps.

(5) Is it necessary to use coupling for the warm-up period of an ES simulation of a typical design day?

The coupling in the warm-up days before the officially simulated design day is necessary, especially for buildings with considerable thermal masses. Otherwise, inconsistent solutions may be observed at 0:00 and 24:00 of the design day. Buildings with light materials may not need coupling for the warm-up days because of the small thermal history effect from the ending hours of the last warm-up day to the beginning hours of the design day. Usually, dynamic bin method can be used in the warm-up period to reduce the computing time due to the similarity of environmental and operating conditions of the warm-up days.

\section{Summary}

With the aim of establishing basic guidelines for the development and application of integrated ES-CFD simulation, this study analyzes the potential building and environmental characteristics that may influence the necessity and effectiveness of applying ES-CFD coupling simulation. These characteristics include environmental conditions, HVAC systems, building occupying and operating conditions, envelope properties, and building sizes. The study conducts a sensitivity analysis of the coupling simulation to these characteristic factors through a 
representative office building in Boston. On the basis of the sensitivity study, the research provides general suggestions on appropriate development and usage of the coupling simulation.

\section{Reference}

Beausoleil-Morrison I. 2000. "The adaptive coupling of heat and air flow modeling within dynamic whole-building simulation,” Ph.D. Thesis, University of Strathclyde, Glasgow, UK.

Chen Q., Glicksman L.R., Yuan X., et al. 1998. "Performance evaluation and development of design guidelines for displacement ventilation,” Final Report for ASHRAE RP-949, MIT, MA.

Fisher D.E. 1995. "An experimental investigation of mixed convection heat transfer in a rectangular enclosure,” Ph.D. Thesis, University of Illinois at Urbana-Champaign, USA.

Hiramatsu T., Harada T., Kato S. et al. 1996. "Study of thermal environment in experimental real-scale atrium,” ROOMVENT '96, 1: 523-530, July 17-19.

Korobov N.M. 1960. "Property and calculation of optimal coefficients,” Doklady Akademi Nauk SSSR, 132: 1009-1012 (English translation: Soviet Mathematics Doklady, 1(1960): 696700).

Lomas K.L. and Eppel H. 1994. "Developing and proving sensitivity analysis techniques for thermal simulation of buildings,” BEPAC'94, 253-280.

Lomas K.J., Eppel H., Martin C., and Bloomfield D. 1994. "Empirical validation of thermal building simulation programs using test room data,” Volume 1 \& 2 : Final Report, IEA Energy Conservation in Buildings and Community Systems Programme Annex 21 and IEA Solar Heating and Cooling Programme Task 12. (IEA 1994)

Negrao C.O.R. 1995. "Conflation of computational fluid dynamics and building thermal simulation,” Ph.D. Thesis, University of Strathclyde, Glasgow, UK.

Saporito A. 1999. "A multi-parameter study into the heating energy consumption of commercial and institutional buildings,” Ph.D. Thesis, South Bank University, London, UK.

Wallentén P. 1998. "Heat flow in building components: experiment and analysis,” Ph.D. Thesis, Lund University, Sweden.

Zhai Z. 2003. "Developing an Integrated Building Design Tool by Coupling Building Energy Simulation and Computational Fluid Dynamics Programs,” Ph.D. Thesis, Massachusetts Institute of Technology, Cambridge, MA, USA.

Zhai Z. and Chen Q. 2003. "Solution Characters of Iterative Coupling between Energy Simulation and CFD Programs,” Energy and Building, 35(5), 493-505.

Zhai Z. and Chen Q. 2005. "Performance of Coupled Building Energy and CFD Simulations," Energy and Buildings, 37(4): 333-344.

Zhai Z., Chen Q., Haves P., and Klems J.H. 2002. “On Approaches to Couple Energy Simulation and Computational Fluid Dynamics Programs,” Building and Environment, 37, 857-864. 